University of Nebraska - Lincoln

DigitalCommons@University of Nebraska - Lincoln

$1-2011$

\title{
The influence of neighborhood density and word frequency on phoneme awareness in 2nd and 4th grades
}

\author{
Tiffany Hogan \\ University of Nebraska - Lincoln, thogan2@unl.edu \\ Ryan P. Bowles \\ Michigan State University, bowlesr@msu.edu \\ Hugh W. Catts \\ University of Kansas, catts@ku.edu \\ Holly L. Storkel \\ University of Kansas, hstorkel@ku.edu
}

Follow this and additional works at: https://digitalcommons.unl.edu/specedfacpub

Part of the Special Education and Teaching Commons

\footnotetext{
Hogan, Tiffany; Bowles, Ryan P.; Catts, Hugh W.; and Storkel, Holly L., "The influence of neighborhood density and word frequency on phoneme awareness in 2nd and 4th grades" (2011). Special Education and Communication Disorders Faculty Publications. 62.

https://digitalcommons.unl.edu/specedfacpub/62

This Article is brought to you for free and open access by the Department of Special Education and Communication Disorders at DigitalCommons@University of Nebraska - Lincoln. It has been accepted for inclusion in Special Education and Communication Disorders Faculty Publications by an authorized administrator of DigitalCommons@University of Nebraska - Lincoln.
} 
Published in Journal of Communication Disorders 44:1 (January-February 2011), pp. 49-58;

doi: 10.1016/j.jcomdis.2010.07.002 Copyright (c) 2010 Tiffany P. Hogan, Ryan P. Bowles, Hugh W. Catts, and Holly L. Storkel. Published by Elsevier Inc. Used by permission.

Submitted March 5, 2010; revised June 3, 2010; accepted July 5, 2010; published online July 17, 2010.

\title{
The influence of neighborhood density and word frequency on phoneme awareness in 2 nd and 4 th grades
}

\author{
Tiffany P. Hogan, University of Nebraska - Lincoln \\ Ryan P. Bowles, Michigan State University \\ Hugh W. Catts and Holly L. Storkel, University of Kansas \\ Corresponding author - T. P. Hogan, 359 Barkley Memorial Center, University of Nebraska - Lincoln, \\ Lincoln, NE 68583, USA; tel 402 472-3911, fax 402 472-7697, email thogan2@unl.edu
}

\begin{abstract}
The purpose of this study was to test the hypothesis that two lexical characteristics - neighborhood density and word frequency - interact to influence performance on phoneme awareness tasks. Phoneme awareness was examined in a large, longitudinal dataset of 2 nd and 4 th grade children. Using linear logistic test model, the relation between words' neighborhood density, word frequency, and phoneme awareness performance was examined across grades while co-varying type and place of deletion. A predicted interaction was revealed: words from dense neighborhoods or those with high frequency were more likely to yield correct phoneme awareness responses across grades. Findings support an expansion of the lexical restructuring model to include interactions between neighborhood density and word frequency to account for phoneme awareness. The article describes the lexical restructuring model, defines neighborhood density and word frequency, identifies how these variables interact to impact phoneme awareness performance, and suggests ways in which future clinical practice may be affected by the study's findings.
\end{abstract}

\section{Introduction}

Phoneme awareness assessment has become a critical part of early identification and diagnosis of reading disability. Phoneme awareness, one's sensitivity to the sound structure of a word, has an important role in early identification of reading impairment because of its causal link to early reading achievement (for reviews, see Adams, 1990; Gillon, 2004). Simply stated, children with poor phoneme awareness are more likely to become poor readers, whereas those with good phoneme awareness often become good readers. Although the relation between phoneme awareness and reading has been explored extensively, less is known about the factors affecting phoneme awareness test performance.

Studies focusing on phoneme awareness test performance have examined issues such as task difficulty (Wagner et al., 1993), picture support (Gibbs, 2003), and construct validity (Anthony and Lonigan, 2004). One area that has received less attention is the influence of lexical characteristics, the sound properties of words, on 
phoneme awareness performance. Lexical characteristics are predicted to influence phoneme awareness performance according to the lexical restructuring model (Metsala and Walley, 1998; Walley et al., 2003). This study examines a longitudinal dataset of item-level phoneme awareness performance to investigate tenets of the lexical restructuring model. Understanding factors associated with phoneme awareness performance will lead to more precise assessments and treatments for children at risk for reading disabilities.

\subsection{The lexical restructuring model}

The lexical restructuring model posits that phoneme awareness is the product of the segmental restructuring of lexical representations that arises as a result of young children's rapid vocabulary growth (Fowler, 1991; Metsala and Walley, 1998; Walley et al., 2003). That is, when children's lexicons contain few words, holistic representations of those words, including minimal phonemic information, are sufficient to differentiate each word from every other word. As children expand their vocabularies, underlying lexical representations must become more phonemically detailed to differentiate newly learned words from existing words in the lexicon. ${ }^{1}$ The lexical restructuring model states that this process of increased phonemic detail can extend into later childhood as children's lexicons expand. Words contain phonemic detail based on lexical characteristics that describe their place in the lexicon. Two lexical characteristics proposed to be associated with phonemic detail are neighborhood density and word frequency.

\subsubsection{Neighborhood density}

Neighborhood density refers to the number of phonologically similar words in the lexicon, and is most often calculated by determining the number of words that are created by adding, deleting, or substituting a single sound in a given word (Luce and Pisoni, 1998). Thus, the word "sit" has 36 neighbors including "spit," "it," and "hit". Words with a high number of neighbors are said to reside in dense neighborhoods, whereas those with few neighbors reside in sparse neighborhoods. Because words from dense neighborhoods have many similar sounding neighbors, those words are hypothesized to contain more phonemic detail; the reverse is true of words from sparse neighborhoods.

According to the lexical restructuring model, words with high neighborhood density should be responded to more accurately than words with low neighborhood density on phoneme awareness tests. This dense word advantage is resultant of more phonemic detail in dense words: words with many neighbors require more phonemic detail to differentiate many similar sounding words. Only a few studies have examined the influence of neighborhood density on phoneme awareness. Metsala (1999) showed that preschool children, ages 3 and 4 years old, were more likely to correctly delete a sound from a word during a phoneme deletion task when the word was from a dense neighborhood. Likewise, a study of phoneme awareness abilities in 5-year-olds showed that children were more likely to correctly identify words as rhyming/nonrhyming when the words were from dense neighborhoods (De Cara and Goswami, 2003). This effect has also been shown in adults (Ventura et al., 2007).

\subsubsection{Word frequency}

Word frequency refers to the number of times a word is heard in the ambient language. The lexical restructuring model proposes that high frequency words have lexical representations with more phonemic detail which translates into higher phoneme awareness performance on high frequency words compared to low frequency words. The model, however, does not specify the mechanism by which frequency contributes to restructuring. It may be that the predicted word frequency effect is a result of token-based restructuring: a word that is heard produced by multiple speakers, multiple times would contain more phonemic detail as a result of

\footnotetext{
1. Others have proposed a similar link between vocabulary acquisition and lexical specificity (e.g., Fowler, 1991; Munson et al., 2005). We chose to test the lexical restructuring model because it poses direct hypotheses for the influence of word-level lexical characteristics on phoneme awareness. Not all available evidence supports the model's tenet that specificity increases through vocabulary growth. In particular, studies of toddlers and infants show that early lexical representations are quite detailed (e.g., Bailey and Plunkett, 2002; Swingley, 2003). Task differences may, in part, explain the conflicting evidence: implicit tasks are used to examine representations in young children whereas studies of preschool and school-age children involve tasks that are explicit in nature. Explicit meta-linguistic reflection may require processing influenced by word similarity. Another possibility is that young children may perceive and store sounds differently than older children (cf. Storkel, 2009; Werker and Curtin, 2005). Clearly, further work is needed to determine if lexical restructuring is a product of vocabulary growth, as stated by the model, or if representations reflect specification according to other factors such as processing differences and/or task demands.
} 
contrasting tokens of phonetic variations of the same word (Richtsmeier et al., 2009; vis-à-vis type-based variation quantified by neighborhood density).

Studies have shown an influence of word frequency on phoneme awareness performance. For example, Troia et al. (1996) found that kindergarten and 2nd-grade children performed with greater accuracy on a phoneme awareness task that involved blending sounds in high frequency words compared to those in low frequency words (see also Roth et al., 2006).

\subsubsection{Interaction between neighborhood density and word frequency}

The lexical restructuring model (Metsala and Walley, 1998) predicts that both word frequency and neighborhood density should affect phoneme awareness performance. It is also plausible that the two lexical characteristics interact to influence performance. To date, one study has investigated the influence of both neighborhood density and word frequency on phoneme awareness performance (Garlock et al., 2001). Garlock et al. orthogonally crossed the word frequency and neighborhood density of words on two phoneme awareness tasks (i.e., initial phoneme isolation and initial phoneme deletion). To capture potential differences across ages, the task was administered to young children (i.e., preschoolers and kindergartners), older children (i.e., 2nd graders), and adults. Analyses based on a composite measure of performance on both phoneme awareness tasks revealed no statistically significant effects or interactions of neighborhood density or word frequency. Unfortunately potential interactions may have been masked by floor and ceiling effects: the tasks were either too difficult - in the sample of young children - or too easy - in the case of older children and adults (Garlock et al., 2001).

\subsection{Study questions and predictions}

In this study we examined the influence of word frequency and neighborhood density on phoneme deletion performance. Based on past findings, we predicted that phoneme awareness accuracy would increase as the neighborhood density of a test word increased. Likewise, we predicted that phoneme awareness accuracy would increase as the frequency of a test word increased. We also considered an interaction between neighborhood density and word frequency. Although the lexical restructuring model holds no specific predictions, we hypothesized that words would reach a threshold of lexical specification due to word frequency or neighborhood density resulting in highly accurate phoneme awareness, such that phoneme awareness performance would be unrelated to neighborhood density in words with high frequency and unrelated to word frequency in words with high neighborhood density.

We also add to extant literature by investigating lexical influences on phoneme awareness across development. Based on past findings, we predicted that grade would be positively related to phoneme awareness accuracy. Unique to this study, we predicted that neighborhood density and word frequency would be related to phoneme awareness performance less so in 4th grade compared to 2nd grade. We reasoned that as children's lexicons expanded across grades neighborhood density would become more equivalent across words (see Storkel, 2004a, 2004c) resulting in a reduced relative impact of dense words on phoneme awareness performance. Likewise, word frequency would increase for most words from 2 nd to 4 th grade reducing the relative impact of words with high frequency on phoneme awareness performance. Taken together we predicted that the interaction between neighborhood density and word frequency on phoneme awareness performance would be less robust in 4 th grade compared to 2 nd grade.

\section{Methods}

\subsection{Participants}

Data included phoneme awareness item-level performance from a sample of children who completed the same phoneme deletion task in 2nd and 4th grades ( $n=194 ; 113$ males, 81 females). These participants were a random subsample of children participating in a longitudinal study of language impairments $(n=570)$. The sample of 570 children was itself a subsample of over 7000 children who took part in an epidemiologic study of language impairments in kindergarten children (see Tomblin et al., 1997). In terms of demographics, the longitudinal sample, and by extension the random sample, was representative of the region in which the sample was recruited (i.e., state of Iowa-midwest portion of the United States of America). 
Table 1. Standard score means and standard deviations $(n=194)$ on a 2nd grade measure of nonverbal intelligence and 2nd and 4th grade measures of word reading and reading comprehension. Raw score means and standard deviations on phonological awareness deletion task.

\begin{tabular}{|c|c|c|c|c|}
\hline & Nonverbal intelligence & $\operatorname{lng}^{\mathrm{b}}$ & Reading comprehension ${ }^{c}$ & Phoneme awareness $^{\mathrm{d}}$ \\
\hline \multicolumn{5}{|c|}{ 2nd grade } \\
\hline Mean & 98.44 & 100.13 & 98.79 & 9.93 \\
\hline$S D$ & 14.47 & 13.19 & 13.66 & 2.34 \\
\hline \multicolumn{5}{|c|}{4 th grade } \\
\hline Mean & Not administered & 100.35 & 98.46 & 11.65 \\
\hline$S D$ & Not administered & 13.32 & 14.02 & 2.26 \\
\hline
\end{tabular}

The phoneme awareness task was administered in kindergarten, 2nd and 4th grades; however, kindergarten data were not examined because very few children completed the phoneme deletion test items. Furthermore, item-level accuracy was not coded when the task was originally scored. For efficiency, we coded itemlevel accuracy for a random subsample which comprised our 194 participants. Table 1 contains the standard score means and standard deviations for the samples on norm-referenced, standardized measures of receptive vocabulary, nonverbal intelligence, word reading, and reading comprehension as well as raw score phoneme awareness test scores in 2nd and 4th grades. As shown, our sample of children included a wide range of performance on all measures indicative of the range of performance in typical 2nd and 4th grade classrooms. All children were native English speakers and each resided in homes in which English was the primary language. No child had a differential diagnosis such as Down syndrome or autism upon enrolment in the longitudinal study in kindergarten.

\subsection{Phoneme awareness test}

Each of the 194 participants was administered a phonological awareness deletion task (Catts et al., 2001) in 2nd and 4th grades. This task was created to assess phonological awareness abilities during the elementary school years. Although it was not created to examine lexical influences on phoneme awareness, the task contains words varying in both neighborhood density and word frequency, as well as type of deletion (i.e., consonant cluster or singleton) and place of deletion (i.e., deletion in initial consonant(s) versus deletion in final consonant(s)). The task consists of 13 word/syllable deletion test items (e.g., say 'cowboy' without 'cow') and 17 phoneme deletion test items (e.g., say 'fat' without /f/). Of the 17 phoneme deletion items, 8 required the deletion of the first sound in a monosyllabic word, whereas the other 9 items required deletion of the final sounds in a monosyllabic word. Likewise, 7 required deletion of a singleton, whereas 9 required deletion of a consonant within a consonant cluster.

In this study, only the phoneme deletion test items from the task were examined (test items 14-30). Phoneme deletion items were selected for two reasons. First, the tenets of the lexical restructuring model relate most directly to phoneme-level awareness tasks. Neighborhood density is a metric that uses phonemes to determine similarity amongst words in the lexicon; hence, a phoneme-based task would likely show the most sensitivity to performance differences based on a phoneme-level measure such as neighborhood density. Second, a phoneme deletion task seemed a logical choice because it consistently serves as the best predictor of future and concurrent word reading skills when compared to other phoneme-level awareness tasks (Torgesen et al., 1994).

The deletion task was administered with no basal rule; however a ceiling rule was implemented: if a participant produced six consecutively tested words incorrectly, the test was discontinued. All participants in the random sample completed all test items. That is, each participant had an opportunity to complete all test items in spite of the ceiling rule. Trained speech-language pathologists and/or educators administered the task at each grade as part of a larger test battery. The task did not show evidence of floor or ceiling effects in either the 2nd and 4 th grade samples. Including only the phoneme deletion test items, the 2nd grade raw score mean was 9.93 $(S D=2.34)$. In 4 th grade the raw score mean was $11.65(S D=2.26$; see Table 1$)$. Using an odd-even split half reliability test, the task evidenced 2nd grade reliability of .86 and 4 th grade reliability of .83 . 
To examine lexical influences on phoneme deletion performance, test words were coded according to neighborhood density and word frequency. Note that performance on 16 of the 17 test words was coded (and included in the analyses); one test word was removed due to its verb tense marking (i.e., test item \#28 fished). Neighborhood density was computed using a 20,000 word electronic dictionary (Webster's Seventh Collegiate Dictionary, 1967) containing phonemic transcriptions of American English. Test words ranged in neighborhood density from 5 to 32 with a mean of $16.5(S D=8.76)$. Word frequency data were also obtained from the electronic dictionary (Kucera and Francis, 1967). Test words ranged in word frequency from 1 to 601 with a mean of 125.81 (SD = 179.27). Table 2 contains test words and their corresponding neighborhood density and word frequency counts. Frequency counts were highly skewed; therefore, we transformed them using a natural $\log$ transformation. To facilitate interpretation of the results, we converted both neighborhood density and logtransformed word frequency counts to $z$ scores based on corresponding counts from 3 to 5 phoneme words extracted from the full electronic dictionary. Neighborhood density and word frequency $z$-score for each test word are listed in Table 2. The mean neighborhood density $z$-score was 1.10 (15.87 neighbors), and the mean $\log$ word frequency $z$-score was 1.07 (equivalent to 41.39 raw frequency), indicating these words were relatively more dense and more frequent than the typical word in the corpus.

Note that neighborhood density and word frequency counts were based on adult data. Previous studies have shown that adult-based data and child-based data produce similar results (e.g., Jusczyk, Luce, and CharlesLuce, 1994). Likewise, adult-based counts have been used in numerous previous studies examining child language (e.g., Newman and German, 2002; Storkel, 2001; Storkel, 2004b). ${ }^{2}$

\subsection{Data analysis}

We employed a multilevel logistic regression predicting a child's response (correct/incorrect) with phoneme awareness test items nested within children and a child-specific intercept to account for individual differences in phoneme awareness. This allowed us to determine the influence of lexical factors, neighborhood density and word frequency, on phoneme awareness performance independent of a child's phoneme awareness. We included one child-level variable, grade, expressed as a dummy variable with $0=$ grade 2 and $1=$ grade 4. Six variables were included as predictors: (1) each word's neighborhood density (z-score), (2) each word's frequency (z-score of the log transformation), (3) an interaction between neighborhood density and word frequency, (4) an interaction between neighborhood density and grade, (5) an interaction between word frequency and grade, and (6) an interaction between neighborhood density, word frequency, and grade. We also included two co-variates to control for non-lexical item effects: type of deletion, a dummy variable indicating whether the deleted phoneme was deleted from a consonant cluster $^{3}$ (coded as 1) or not (i.e., singleton deletion coded as 0 ), and place of deletion (deletion in initial consonant or consonant cluster coded as 0 , deletion in final consonant or consonant cluster coded as 1), both of which have been shown to affect the difficulty of phoneme deletion (Bruck and Treiman, 1990; Catts et al., 1996). The model was estimated using PROC NLMIXED. The script is available by request.

\section{Results}

For descriptive purposes, the percentage of children who were able to correctly delete the target phoneme on each test word is presented in Table 2. Results from the multilevel logistic regression are summarized in Table 3. Consistent with standard logistic regression, we discuss results in terms of odds ratios, which describe the relative odds of a correct response.

The lexical restructuring model predicts that words with higher neighborhood density will show more accurate phoneme deletion compared to those with lower neighborhood density. This prediction was supported. For each standard deviation increase in neighborhood density, children were 2.09 more likely to respond

2. Child counts were recently made available (Storkel and Hoover, 2010). Correlations between our adult counts and the new child counts were high, as expected (word frequency: $R=.71$; neighborhood density: $R=.97$ ). Adult counts were used for analyses because child counts were not available for 3 of our test words. This is likely the result of a smaller child database, which includes 4832 words; the adult database includes over 20,000 words.

3. We note that type of deletion is not entirely clear for one word (/fju/; see Davis and Hammond, 1995; Gierut and O'Connor, 2002); however results were not different regardless of the word's 'type of deletion' coding. 


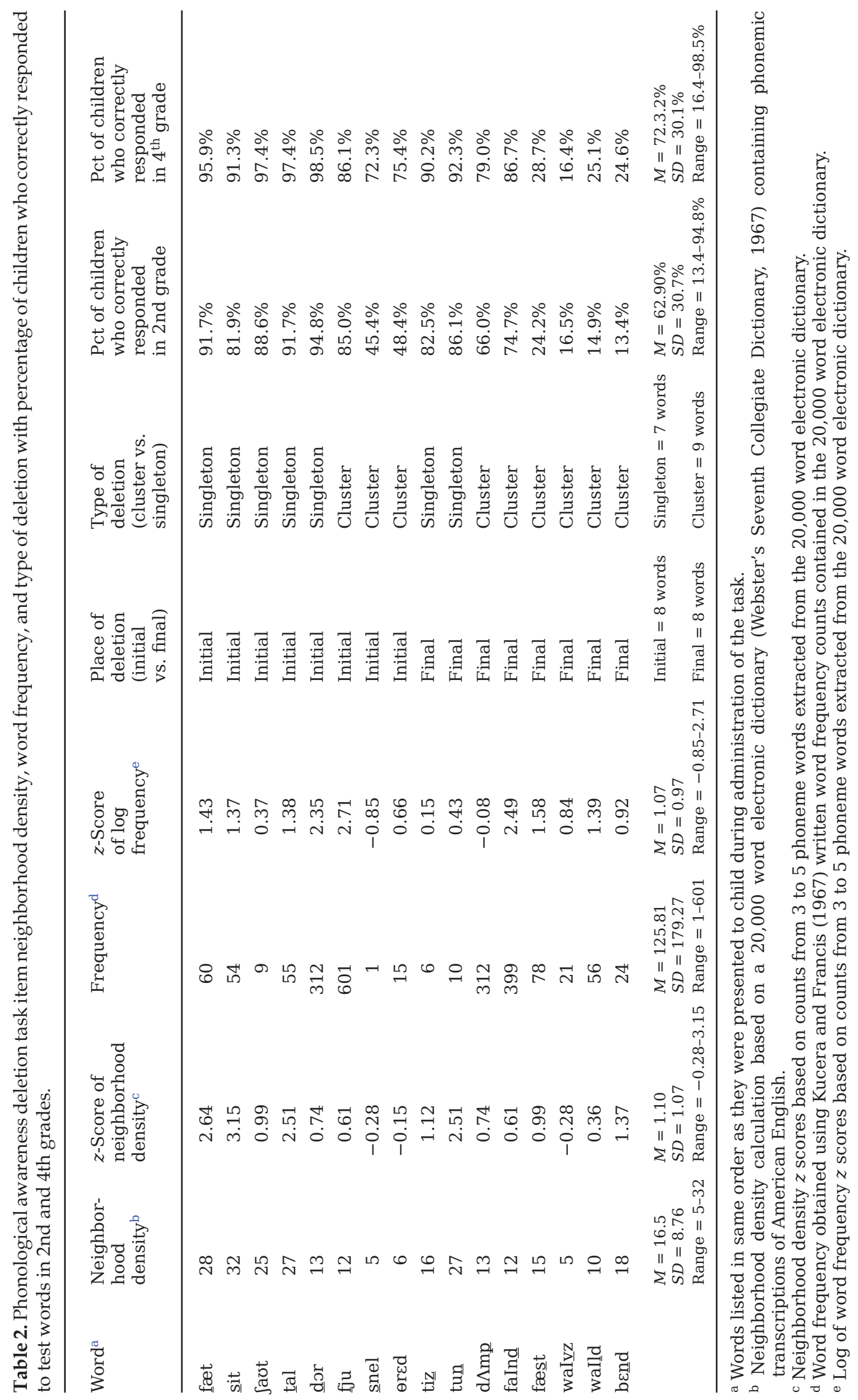


Table 3. Results of multilevel logistic regression.

\begin{tabular}{lcc}
\hline Predictor & Odds ratio & $95 \%$ CI \\
\hline Density & $2.09^{\mathrm{a}}$ & {$[1.63,2.69]$} \\
Frequency & $2.06^{\mathrm{b}}$ & {$[1.81,2.36]$} \\
Grade & $2.48^{\mathrm{c}}$ & {$[1.89,3.27]$} \\
Interaction between density and frequency & 0.45 & {$[0.37,0.55]$} \\
Interaction between density and grade & 0.85 & {$[0.65,1.10]$} \\
Interaction between frequency and grade & 0.69 & {$[0.58,0.82]$} \\
Three-way interaction between density, frequency, and grade & 1.35 & {$[1.06,1.73]$} \\
Type of deletion & $0.12^{\mathrm{c}}$ & {$[0.09,0.16]$} \\
Place of deletion & $6.14^{\mathrm{c}}$ & {$[4.97,7.60]$} \\
\hline
\end{tabular}

95\% CI is the $95 \%$ confidence intervals. Confidence intervals containing 1 are nonsignificant.

${ }^{a}$ Odds ratio for $z$-score.

b Odds ratio for $z$-score of natural log transform.

${ }^{\mathrm{c}}$ Odds ratio for dummy variable.

correctly $(p<.001)$. There was no evidence that the effect of neighborhood density on phoneme deletion changed across grades, as indicated by the nonsignificant interaction of density and grade (odds ratio $=.85$, $p=.22)$.

The lexical restructuring model predicts that words with higher word frequency will show more accurate phoneme deletion compared to those with lower word frequency. This prediction was also supported. For each standard deviation increase in log-transformed word frequency, children were 2.07 times more likely to respond correctly $(p<.001)$. The effect of word frequency was moderated by grade, such that the effect was .69 times as large in 4 th grade compared to 2 nd grade $(p<.001)$, leading to an overall odds ratio of 1.43 for 4 th grade $(2.07 \times .69)$.

The lexical restructuring model does not hold direct predictions for an interaction between neighborhood density and word frequency; however we expected a threshold effect in which the effect of neighborhood density on phoneme awareness performance would be lower with high word frequency and, conversely, the effect of word frequency would be lower with high neighborhood density. This prediction was supported. A negative interaction was found between neighborhood density and word frequency (odds ratio $=0.45, p<.001$ ): as word frequency increases, the effect of neighborhood density on phoneme deletion was reduced. There was also a significant three-way interaction, such that the interaction is smaller in fourth grade than in second grade (odds ratio $=0.45 \times 1.35=0.61, p=.02)$.

\section{Discussion}

This study sought to determine the influence of two lexical characteristics - neighborhood density and word frequency - on phoneme awareness performance in a longitudinal sample of children tested in 2 nd and 4 th grades. Of particular interest was a predicted interactive influence of neighborhood density and word frequency on phoneme awareness performance. Further, the influence of these characteristics was examined during development as children progressed from 2 nd to 4 th grade.

Based on the tenets of the lexical restructuring model coupled with past research findings, it was predicted that words from dense neighborhoods would yield more accurate responses than words from sparse neighborhoods on a phoneme awareness test (De Cara and Goswami, 2003; Metsala, 1999). Likewise, it was predicted that high frequency words would yield higher accuracy than words with low frequency words (Roth et al., 2006). Both predictions were confirmed.

Further, it was predicted that word frequency and neighborhood density would negatively interact to influence phoneme awareness accuracy. This prediction was confirmed: as word frequency increased, the effect of neighborhood density on phoneme deletion was reduced. The reverse was also true. This interaction is interpreted in a framework in which type-based variations (indexed by neighborhood density) or token-based variations (indexed by word frequency) increase word-level phonemic specification which in turn results in wordspecific increases in phoneme awareness accuracy. According to this explanation, words with high token-based counts (i.e., high word frequency) do not benefit from phoneme awareness accuracy gains from additional typebased variation (i.e., high neighborhood density). Inversely, adding token-based variation by way of increased 
word frequency results in limited additional specification of a word's lexical representation in words with high type-based variations (i.e., high neighborhood density). Based on these findings, we propose that the lexical restructuring model should be expanded to include interactive effects of neighborhood density and word frequency: restructuring is the result of either type-based variation - indexed by neighborhood density - or tokenbased variations - indexed by word frequency. We have labeled this the threshold effect in which a word would reach a 'threshold' of phoneme awareness accuracy due to type- or token-based word-specific lexical specification leaving little room for performance increases from another form of variation (see also Storkel, 2004a for a similar description of threshold effects on word learning).

In addition to finding a significant interaction between neighborhood density and word frequency, developmental differences were also revealed. As expected, phoneme awareness accuracy increased from 2nd grade to 4 th grade. Further, we predicted that the effect of lexical characteristics on performance would decrease from 2nd to 4th grade. We reasoned that vocabulary growth would mute the relative difference between words' neighborhood density and word frequency in turn reducing the effect of both on phoneme awareness performance across grades. This prediction was confirmed: the interactive influence of neighborhood density and word frequency on phoneme awareness was present at both grades; however the effect was slightly reduced in 4th grade.

\subsection{Clinical implications}

Predictions from the lexical restructuring model, supported by this study, have potential to inform the assessment of phoneme awareness. Recent policy changes have focused on response to intervention (RTI) as a model for diagnosing reading disability in the early grades. Implementation of RTI models requires multiple measures of pre-reading skills at numerous time points as a way to track change over time. Based on the results of this study, systematically varying the neighborhood density and word frequency of words used on tests of phoneme awareness may serve as a way to create meaningful probes: words from dense neighborhoods or with high frequency would be predicted to be the easiest phoneme awareness test items across the grades, while those from sparse neighborhoods or with low word frequency would be the most difficult. It would be predicted that children who exhibit different patterns may be at risk for reading and language learning difficulties. Likewise attention to these lexical characteristics in phoneme awareness treatment (cf. Morrisette and Gierut, 2002) may increase treatment efficacy. Clinical implications are given with caution because the current study did not address these predictions. Clearly future studies are needed.

\subsection{Limitations}

The lexical restructuring model posits neighborhood density as one metric for quantifying word-level phoneme specificity resultant of vocabulary growth. However other lexical characteristics, such as phonotactic probability (Munson et al., 2005) and sound-to-letter correspondences (Ventura et al., 2007), are correlated with neighborhood density and have been shown to influence phoneme specificity as well. Future work will need to determine how an array of characteristics associated with individual words interact to influence restructuring and in turn phoneme awareness. Likewise, this study examined these characteristics in one type of phoneme awareness task, phoneme deletion. Lexical influences on phoneme awareness should be examined in a variety of phonological awareness tasks in relation to individual differences in vocabulary acquisition and associated child-specific neighborhood density and word frequency.

This study involved an examination of the influence of lexical characteristics on phoneme awareness performance using item-level data not created for this purpose. However, it is important to make use of rich datasets to take a preliminary look at theoretically driven research questions while acknowledging limitations of post hoc analyses. ${ }^{4}$ We included co-variates, place of deletion and type of deletion, to statistically account for influences on phoneme awareness performance not controlled across our lexical characteristics of interest. The predicted interaction between neighborhood density and word frequency was revealed with these controls in place bolstering the validity of the results. However, it is imperative to conduct a controlled experimental study to confirm these findings.

4. See volume 41, issue 1 of Language Speech and Hearing Services in Schools, a special edition devoted to promoting the use of existing databases to explore theory-driven questions. 


\subsection{Conclusions}

The purpose of this study was to test the hypothesis that neighborhood density and word frequency would interact to influence phoneme awareness. Findings supported a threshold effect in which words with high neighborhood density or high word frequency were more likely to be correct on our phoneme deletion task. This interaction was present in both 2 nd and 4 th grades although the effect was less robust in 4 th grade. Based on these findings we propose that the lexical restructuring model be amended to include these interactions due to token-based variations (i.e., word frequency) or type-based variations (i.e., neighborhood density).

\section{Acknowledgments}

This research was supported by NIH Grants awarded to Tiffany Hogan (DC009667), Hugh Catts (DC02726), and Holly Storkel (DC04781, DC08095). NIH training grant DC000052 also supported this research. Portions of the research reported here were presented at the 2004 American Speech-Language-Hearing Association Annual Convention in Philadelphia, PA. The completion of this study was aided considerably by a valuable research team comprising the following: J. Bruce Tomblin, Paula Buckwalter, Marlea O'Brien, Connie Ferguson, Jodi Schwartz, Juanita Limas, Amy Kundel, and Jacqueline Daniels.

\section{Appendix A. Continuing education}

1. Lexical characteristics of words include:

a. neighborhood density

b. word frequency

c. both

d. syntactic variation

2. 'cat' is a phonological neighbor of 'patch'

True or False

3. Words with high word frequency or high neighborhood density are more likely to be correct on a phoneme awareness test.

True or False

4. The lexical restructuring model states that restructuring of words can continue into later childhood.

True or False

5. The interactive effect of word frequency and neighborhood density of phoneme awareness accuracy

from 2 nd to 4 th grade.
a. decreased
b. increased
c. stabilized
d. improved

\section{References}

Adams, 1990 M. J. Adams, Beginning to read: Thinking and learning about print, MIT Press, Cambridge, MA (1990).

Anthony and Lonigan, 2004 J. L. Anthony and C. J. Lonigan, The nature of phonological awareness: Converging evidence from four studies of preschool and early grade school children, Journal of Educational Psychology 96 (1) (2004), pp. 43-55.

Bailey and Plunkett, 2002 T. M. Bailey and K. Plunkett, Phonological specificity in early words, Cognitive Development 17 (2002), pp. 1265-1282.

Bruck and Treiman, $1990>$ M. Bruck and R. Treiman, Phonological awareness and spelling in normal children and dyslexics: The case of initial consonant clusters, Journal of Experimental Child Psychology 50 (1990), pp. 156-178.

Catts et al., 2001 H. Catts, M. Fey, X. Zhang, and J. B. Tomblin, Estimating the risk of future reading difficulties in kindergarten children: A research-based model and its clinical implementation, Language, Speech, and Hearing Services in Schools 32 (2001), pp. 38-50.

Catts et al., 1996 H. Catts, K. Wilcox, C. Wood-Jackson, L. Larrivee, and V. Scott, Toward an understanding of phonological awareness. In: C. K. Leong and R. M. Joshi, Editors, Cross-language studies of learning to read and spell: Phonologic and orthographic processing, Kluwer Academic Publishers, Norwell, MA (1996).

Davis and Hammond, 1995 S. Davis and M. Hammond, On the status of on-glides in American English, Phonology 12 (1995), pp. $159-182$.

De Cara and Goswami, 2003 B. De Cara and U. Goswami, Phonological neighbourhood density: Effects in a rhyme awareness task in five-year-old children, Journal of Child Language 30 (3) (2003), pp. 695-710.

Fowler, 1991 A. Fowler, How early phonological development might set the stage for phoneme awareness. In Phonological processes in literacy, pp. 97-117, Lawrence Erlbaum Associates (1991). 
Hogan et al. in Journal of Communication Disorders 44 (2011)

Garlock et al., 2001 V. M. Garlock, A. C. Walley, and J. L. Metsala, Age-of-acquisition, word frequency, and neighborhood density effects on spoken word recognition by children and adults, Journal of Memory and Language 45 (2001), pp. 468-492.

Gibbs, 2003 S. Gibbs, Do pictures make a difference? A test of the hypothesis that performance in tests of phonological awareness is eased by the presence of pictures, Educational Psychology in Practice 19 (3) (2003), pp. 219-228.

Gierut and O'Connor, 2002 J. A. Gierut and K. M. O'Connor, Precursors to onset clusters in acquisition, Journal of Child Language 29 (2002), pp. 495-517.

Gillon, 2004 G. T. Gillon, Phonological awareness: From research to practice, Guilford Press, New York (2004).

Jusczyk et al., $1994>$ P. W. Jusczyk, P. A. Luce, and J. Charles-Luce, Infants' sensitivity to phonotactic patterns in the native language, Journal of Memory and Language 33 (1994), pp. 630-645.

Kucera and Francis, 1967 H. Kucera and W. N. Francis, Computational analysis of present-day American English, Brown University, Providence, RI (1967).

Luce and Pisoni, 1998 P. A. Luce and D. B. Pisoni, Recognizing spoken words: The neighborhood activation model, Ear and Hearing 19 (1998), pp. 1-36.

Metsala, 1999 J. L. Metsala, Young children's phonological awareness and nonword repetition as a function of vocabulary development, Journal of Educational Psychology 91 (1999), pp. 3-19.

Metsala and Walley, 1998 J. L. Metsala and A. C. Walley, Spoken vocabulary growth and the segmental restructuring of lexical representations: Precursors to phonemic awareness and early reading ability. In: J. L. Metsala and L. C. Ehri, eds., Word recognition in beginning literacy, Lawrence Erlbaum Associates, Inc., Mahwah, NJ (1998), pp. 89-120.

Morrisette and Gierut, $2002 \longrightarrow$ M. L. Morrisette and J. A. Gierut, Lexical organization and phonological change in treatment, Journal of Speech, Language, and Hearing Research 45 (2002), pp. 143-159.

Munson et al., $2005 \longrightarrow$ B. Munson, B. Kurtz and J. Windsor, The influence of vocabulary size, phonotactic probability, and wordlikeness on nonword repetitions of children without specific language impairment, Journal of Speech, Language, and Hearing Research 48 (2005), pp. 1033-1047.

Newman and German, $2002 \rightarrow$ R. S. Newman and D. J. German, Effects of lexical factors on lexical access among typical languagelearning children and children with word-finding difficulties, Language and Speech 45 (3) (2002), pp. 285-317.

Richtsmeier et al., 2009 P. T. Richtsmeier, L. Gerken, L. Goffman, and T. Hogan, Statistical frequency in perception affects children's lexical production, Cognition 111 (2009), pp. 372-377.

Roth et al., 2006 F. P. Roth, G. A. Troia, C. K. Worthington, and D. Handy, Promoting awareness of sounds in speech (PASS): The effects of intervention and stimulus characteristics on the blending performance of preschool children with communication impairments, Learning Disability Quarterly 29 (2006), pp. 67-88.

Storkel, 2001 H. L. Storkel, Learning new words: Phonotactic probability in language development, Journal of Speech, Language, and Hearing Research 44 (2001), pp. 1321-1337.

Storkel, 2004a - H. L. Storkel, Do children acquire dense neighbourhoods? An investigation of similarity neighbourhoods in lexical acquisition, Journal of Applied Psycholinguistics 25 (2004), pp. 201-221.

Storkel, 2004b $>$ H. L. Storkel, The emerging lexicon of children with phonological delays: Phonotactic constraints and probability in acquisition, Journal of Speech, Language, and Hearing Research 47 (5) (2004), pp. 1194-1212.

Storkel, 2004c $\rightarrow$ H. L. Storkel, Methods for minimizing the confounding effects of word length in the analysis of phonotactic probability and neighborhood density, Journal of Speech, Language and Hearing Research 47 (6) (2004), pp. 1454-1468.

Storkel, 2009 H. L. Storkel, Developmental differences in the effects of phonological, lexical, and semantic variables on word learning by infants, Journal of Child Language 36 (2009), pp. 291-321.

Storkel and Hoover, $2010 \rightarrow$ H. L. Storkel and J. Hoover, An on-line calculator to compute phonotactic probability and neighborhood density based on child corpora of spoken American English, Behavior Research Methods 42 (2010), pp. 497-506.

Swingley, 2003 D. Swingley, Phonetic detail in the developing lexicon, Language and Speech 46 (2003), pp. 265-294.

Tomblin et al., 1997 J. B. Tomblin, N. Records, P. Buckwalter, X. Zhang, E. Smith, and M. O'Brien, Prevalence of specific language impairment in kindergarten children, Journal of Speech, Language, and Hearing Research 40 (1997), pp. 1245-1260.

Torgesen et al., $1994 \rightarrow$ J. K. Torgesen, R. K. Wagner, and C. A. Rashotte, Longitudinal studies of phonological processing and reading, Journal of Learning Disabilities 27 (5) (1994), pp. 276-286.

Troia et al., 1996 G. A. Troia, F. P. Roth, and G. H. Yeni-Komshian, Word frequency and age effects in normally developing children's phonological processing, Journal of Speech and Hearing Disorders 39 (1996), pp. 1099-1108.

Ventura et al., $2007-$ P. Ventura, R. Kolinsky, S. Fernandes, L. Querido, and J. Morais, Lexical restructuring in the absence of literacy, Cognition 105 (2007), pp. 334-361.

Wagner et al., $1993-$ R. K. Wagner, J. K. Torgesen, P. Laughon, K. Simmons, and C. A. Rashotte, Development of young readers' phonological processing abilities, Journal of Educational Psychology 85 (1993), pp. 83-103.

Walley et al., $2003 \longrightarrow$ A. C. Walley, J. L. Metsala, and V. M. Garlock, Spoken vocabulary growth: Its role in the development of phoneme awareness and early reading ability, Reading and Writing: An Interdisciplinary Journal 16 (2003), pp. 5-20.

Webster's Seventh Collegiate Dictionary, 1967 Webster's Seventh Collegiate Dictionary. (1967). Los Angeles: Library Reproduction Service.

Wechsler, 1989 D. Wechsler, Wechsler Preschool and Primary Scale Intelligence - Revised, Psychological Corporation, New York (1989).

Werker and Curtin, 2005 J. F. Werker and S. Curtin, PRIMIR: A developmental framework of infant speech processing, Language Learning and Development 1 (2) (2005), pp. 197-234.

Woodcock, 1987 R. Woodcock, Woodcock Reading Mastery Tests - Revised, American Guidance Service, Circle Pines, MN (1987). 